\title{
Correction to: Modelling the Asymmetrical Relationships between Digitalisation and Sustainable Competitiveness: A Cross-Country Configurational Analysis
}

\author{
Mohammad Soltani Delgosha ${ }^{1} \cdot$ Tahereh Saheb $^{2} \cdot$ Nastaran Hajiheydari $^{3}$ \\ Published online: 9 July 2020 \\ (C) Springer Science+Business Media, LLC, part of Springer Nature 2020
}

\section{Correction to: Information Systems Frontiers (2020)}

https://doi.org/10.1007/s10796-020-10029-0

Due to typesetting mistake, the big circles in Tables 4 and 5 became same size with the bullets.

The original version has been corrected.

Publisher's Note Springer Nature remains neutral with regard to jurisdictional claims in published maps and institutional affiliations.

The online version of the original article can be found at https://doi.org/ 10.1007/s10796-020-10029-0

Nastaran Hajiheydari

N.hajiheydari@sheffield.ac.uk; nhheidari@ut.ac.ir

Mohammad Soltani Delgosha

Mohammad.soltanidelgosha@uwe.ac.uk

Tahereh Saheb

t.saheb@modares.ac.ir

1 UWE Business School, University of the West of England, Bristol, UK

2 Tarbiat Modares University, Tehran, Iran

3 Sheffield University Management School, University of Tehran, Room: C094, Conduit Rd S10 1FL, Sheffield, UK 